\title{
A Message from the Editor-in-Chief Regarding Rapid Communications
}

In January 1999, The Journal of Neuroscience will launch Rapid Communications, an online-only section of the Journal devoted to brief articles that will be published within 1 month of acceptance. Rapid Communications represents another exciting step forward in the Journal's commitment to serve its readership by staying at the forefront of electronic publication. It will build on the outstanding success of the online version of the regular Journal, whose usage has grown dramatically since it was launched in the summer of 1996.

The purpose of this message is to encourage you as a neuroscientist to consider submitting exciting and timely work from your laboratory to Rapid Communications. There are four main reasons why Rapid Communications will be an attractive venue for publishing short articles: its speed, its wide readership base, its imprimatur of quality and prestige, and its assured stability.

Speed. Rapid Communications will allow exceptionally fast publication. The time from acceptance to publication will be 1 month, without any sacrifice in the quality of copyediting and composition service. Because Rapid Communications articles will be shorter, review time will be reduced, so that the time between arrival of a manuscript and the initial editorial decision is expected to average less than 1 month.

Assured large readership base. To maximize visibility and accessibility, the Rapid Communications section of the Journal will be made universally accessible on the World Wide Web. In addition, the automatic E-mailing of the Table of Contents assures that all 28,000 Society for Neuroscience members are alerted to the latest articles. Rapid Communications articles will have special prominence by being placed at the top of each Table of Contents (including, of course, the hard copy issue as well). Online usage has doubled in the past year, and it is expected to increase even further in the coming year for several complementary reasons: (1) online and hard copy versions will automatically be included together in all institutional subscriptions, starting in January 1999; (2) a new Research Alert service that provides for personalized search criteria will further accelerate the trend towards online usage; and (3) Rapid Communications itself will generate a surge of interest among online readers, who will need only to click a button to satisfy their curiosity about what's in the premiere Rapid Communications articles.

Quality and prestige. Papers published in Rapid Communications will have all of the prestige and imprimatur of quality that has long been associated with The Journal of Neuroscience. The editors are committed to maintaining the same high standards for Rapid Communications manuscripts that have been firmly established for the regular Journal. This will be achieved by handling all manuscripts through the same senior editors and reviewing editors, using the same review criteria and guidelines.

Assured stability. The Society is committed to maintaining the online Journal as a securely archived entity that remains fully accessible to the neuroscience community. Because Rapid Communications articles will be an integral part of the online Journal, they will retain long-term stability and accessibility.

Hard copy reprints will be available for all Rapid Communications articles. Color figures will be published without charge (although there will be a charge for color figures if reprints are ordered).

Rapid Communications has undergone an intensive planning and development process since the idea was initiated by Mike Gazzaniga in 1996. The concept has been enthusiastically endorsed by Council, the Publications Committee, and the editors of the Journal. Additional information regarding Rapid Communications, including special instructions for authors, can be obtained at the Society's Web site (http://www.sfn.org/RapidComm). Questions can be E-mailed to JN@sfn.org.

Manuscripts submitted to Rapid Communications will be processed for review starting on October 1, 1998. I encourage all members of the neuroscience community to participate in this exciting new venture in electronic publishing.

David Van Essen

Editor-in-Chief

The Journal of Neuroscience 